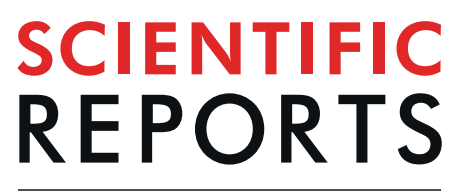

natureresearch

\title{
Micromonospora zhangzhouensis sp. nov., a Novel Actinobacterium Isolated from Mangrove Soil, Exerts a Cytotoxic Activity in vitro
}

Geyi Fu' ${ }^{1}$, Ruijun Wang ${ }^{1}$, Jinglin Ding ${ }^{2}$, Huan $\mathrm{Qi}^{3}$, Zhe Zhao ${ }^{4}$, Can Chen ${ }^{1}$, Hui Zhang ${ }^{3,5}$, Zhenglian $\mathrm{Xue}^{5}$, Jidong Wang ${ }^{3,5^{*}} \& \mathrm{Min} \mathrm{Wu}^{1,4^{*}}$

A new bacterial strain, designated $\mathrm{HM} 134^{\top}$, was isolated from a sample of soil collected from a Chinese mangrove Avicennia marina forest. Assessed by a polyphasic approach, the taxonomy of strain $\mathrm{HM}^{134^{\top}}$ was found to be associated with a range of phylogenetic and chemotaxonomic properties consistent with the genus Micromonospora. Phylogenetic analysis based on the 16s rRNA gene sequence indicated that strain $\mathrm{HM}^{134^{\top}}$ formed a distinct lineage with the most closely related species, including $M$. rifamycinica AM105 ${ }^{\top}$, M. wenchangensis CCTCC AA $2012002^{\top}$ and M. mangrovi $2803 \mathrm{GPT} 1-18^{\top}$. The ANI values between strain $\mathrm{HM}{ }^{\top} 4^{\top}$ and the reference strains ranged from $82.6 \%$ to $95.2 \%$, which was below the standard criteria for classifying strains as the same species (96.5\%). Strain $\mathrm{HM} 134^{\top}$ and related species shared in silico dDDH similarities values below the recommended $70 \%$ cut-off for the delineation of species (range from 25.7-62.6\%). The DNA G+C content of strain HM134 ${ }^{\top}$ was $73.2 \mathrm{~mol} \%$. Analysis of phylogenetic, genomic, phenotypic and chemotaxonomic characteristics revealed that strain HM134 $^{\top}$ is considered to represent a novel species of the genus Micromonospora, for which the name $M$. zhangzhovensis sp. nov. is proposed. The extract of strain $\mathrm{HM}^{134^{\top}}$ was demonstrated to exhibit cytotoxic activity against the human cancer cell lines HepG2, HCT-116 and A549. Active substance presented in the fermentation broth of strain $\mathrm{HM} 134^{\top}$ was isolated by bioassay-guided analysis and purified afterwards. A new derivative of diterpenoid was identified through electrospray ionizing mass spectrometry (MS) and nuclear magnetic resonance (NMR). The compound showed different cytotoxic activities against cancer cells, with the highest cytotoxicity against HCT-116, corresponding to $\mathrm{IC}_{50}$ value of $38.4 \mu \mathrm{g} / \mathrm{mL}$.

The genus Micromonospora, which belongs to the family Micromonosporaceae was first proposed by Ørskov ${ }^{1}$ with Micromonospora chalcea as its type species. Micromonospora species are widely distributed in nature and thrive in different environments, such as sandstone, soil, water, plants, insects, root nodules and mangrove sediments ${ }^{2-10}$. The genus has long been known as a significant source of secondary metabolites with diverse chemical structures and biological activities and is second only to Streptomyces in this respect, synthesizing up to 740 different bioactive microbial metabolites ${ }^{11}$. Members of the genus Micromonospora are Gram-positive, aerobic, non-motile spores directly from substrate hyphae and lack aerial mycelia. In general, the pigments of their mycelia are in orange, red or brown color. The range of $\mathrm{G}+\mathrm{C}$ content of the DNA was $71.1-73.8 \mathrm{~mol} \%{ }^{12}$.

Mangroves are a unique woody plant community inhabiting intertidal coasts between land and sea, covering approximately $60-75 \%$ of the world's tropical and subtropical coastlines and featuring in its ecological environment and high productivity ${ }^{13}$. Given that mangrove ecosystems have high salinity, strong winds, extreme tides, high temperature, anaerobic soils and high muddiness characteristics ${ }^{14}$, utilization of the mangrove microorganism resource with the potential of producing bioactive metabolites has increasingly received attention. Previous studies provided evidence that mangrove soil contains rich populations of Micromonosporae ${ }^{15}$. Furthermore,

\footnotetext{
${ }^{1}$ Ocean College, Zhejiang University, Zhoushan, China. ${ }^{2}$ Zhoushan Tourism \& Health College, Zhoushan, China. ${ }^{3}$ Zhejiang Key Laboratory of Antifungal Drugs, Zhejiang Hisun Pharmaceutical Co., Ltd., Taizhou, China. ${ }^{4}$ College of Life Sciences, Zhejiang University, Hangzhou, China. ${ }^{5}$ College of Biochemical Engineering, Anhui Polytechnic University, Wuhu, China. *email: jdwang@hisunpharm.com; wumin@zju.edu.cn
} 
several novel species of the genus Micromonospora have been identified from marine and mangrove environments lately, including Micromonospora haikouensis ${ }^{16}$, Micromonospora rhizosphaerae ${ }^{5}$, Micromonospora zhanjiangensis $^{17}$, Micromonospora fluostatini ${ }^{18}$, Micromonospora sediminis ${ }^{19}$, Micromonospora sonneratiae ${ }^{20}$, Micromonospora mangrove $^{21}$ and Micromonospora maritima ${ }^{22}$. Strains representing species of the genus Micromonospora have been recognized as important sources of bioactive secondary metabolites: gentamicin, sagamicin, sisomicin, verdamicin, everninomicin, lupinacidins A-C, netamicin, tetrocracin A, diazepinomicin and yangpumicin ${ }^{11,12,23,24}$. These findings suggested that the genus Micromonospora should remain a focus of research for the discovery of new bioactive metabolites. In the present study, a novel strain of the genus Micromonospora collected from the rhizosphere soil of the mangrove in Fujian, China was discovered. The extract from this novel strain exerted antitumor activity, in addition the activity compound present in the extract was characterized.

\section{Results}

Phylogenetic and genomic analyses. The 16S rRNA gene sequence of strain HM134 $4^{\mathrm{T}}$ comprised 1480 nt. According to the analysis using the EzTaxon server, strain $\mathrm{HM} 134^{\mathrm{T}}$ was most closely related to M. rifamycinica AM105 $5^{\mathrm{T}}(99.6 \%)$, M. wenchangensis CCTCC AA $2012002^{\mathrm{T}}(99.4 \%)$, Micromonospora oryzae CP2R9-1 ${ }^{\mathrm{T} 25}$ (99.3\%), Micromonospora harpali NEAU-JC6 ${ }^{\mathrm{T}} 10$ (99.2\%), M. mangrove $2803 \mathrm{GPT} 1-18^{\mathrm{T}}$ (99.1\%), Micromonospora krabiensis DSM 45344 26 (99.0\%), M. carbonacea DSM $43168^{\mathrm{T} 27}(99.0 \%)$, M. haikouensis $232617^{\mathrm{T}}(99.0 \%)$, Micromonospora schwarzwaldensis HKI064 ${ }^{\mathrm{T} 28}$ (99.0\%), Micromonospora sediminicola SH2-13 ${ }^{\mathrm{T} 29}(98.8 \%)$, Micromonospora humi DSM $45647^{\mathrm{T} 30}(98.8 \%)$, M. maritima D10-9-5 ${ }^{\mathrm{T}}(98.8 \%)$, Micromonospora phytophila SG15 ${ }^{\mathrm{T} 31}$ (98.8\%), Micromonospora coxensis DSM $45161^{\mathrm{T} 31}(98.8 \%)$ and shared less than $98.7 \%$ sequence similarity with the type strains of other species of the genus Micromonospora. The phylogenetic trees reconstructed based on the neighbor-joining (Fig. 1), maximum-parsimony (See Supplementary Fig. S1), maximum-likelihood (See Supplementary Fig. S2) methods and ARB program (See Supplementary Fig. S3). According to the neighbor-joining, maximum-parsimony and maximum-like methods, strain $\mathrm{HM} 134^{\mathrm{T}}$ stably formed a distinct lineage with the following related species: M. rifamycinica AM105 ${ }^{\mathrm{T}}$, M. wenchangensis CCTCC AA $2012002^{\mathrm{T}}$ and $M$. mangrovi $2803 \mathrm{GPT} 1-18^{\mathrm{T}}$. The phylogentic tree using ARB program also indicated that strain $\mathrm{HM} 134^{\mathrm{T}}$ fell in the clade with $M$. wenchangensis CCTCC AA $2012002^{\mathrm{T}}$ and $M$. rifamycinica AM105 ${ }^{\mathrm{T}}$. The DNA G+C content of strain HM134 $4^{\mathrm{T}}$ was $73.2 \mathrm{~mol} \%$ (in silico), which is similar to those reported from most closely related species $(71.0-71.7 \mathrm{~mol}$ $\%)$ and other strains in the Micromonospora genus. The complete genome sequence of strain HM134 ${ }^{\mathrm{T}}$ has been deposited at DDBJ/ENA/GenBank under the accession CP041061. The gene sequence gyr B was obtained from genome sequence (CP041061 from 7617 to 9563) and the phylogenetic tree based on gyr $\mathrm{B}$ gene sequence of $\mathrm{HM} 134^{\mathrm{T}}$ and other reference strains revealed that $\mathrm{HM} 134^{\mathrm{T}}$ should be placed in genus Micromonospora and most closely related to M. wenchangensis CCTCC AA $2012002^{\mathrm{T}}$ (Fig. 2). The ANI values between strain HM134 and additional reference strains were in the range 82.6-95.2\% (See Supplementary Table S1), which was below the standard criteria for classifying strains as the same species $(96.5 \%)^{32}$. Meanwhile, the in silico dDDH values between strain $\mathrm{HM} 134^{\mathrm{T}}$ and related species were range from $25.7-62.6 \%$, which are below the recommended $70 \%$ cut-off for the delineation of species ${ }^{12}$ (See Supplementary Table S1), supporting that strain $\mathrm{HM}_{134^{\mathrm{T}}}$ can be considered to represent a novel species of genus Micromonospora.

Chemotaxonomic analysis. The major respiratory quinone of strain HM134 ${ }^{\mathrm{T}}$ was identified as MK-10(H6). The absence of MK-10(H4), MK-9(H6) and MK-9(H4) could distinguish HM134 ${ }^{\mathrm{T}}$ from its close neighbor strains. The cell wall of strain $\mathrm{HM} 134^{\mathrm{T}}$ contained meso-diaminopimelic. Whole-cell hydrolysates predominantly contained xylose, arabinose and glucose. The detailed fatty acid and polar lipid profiles of strain HM134 ${ }^{\mathrm{T}}$ are shown in Supplementary Table S2 and Fig. S4, respectively. The most abundant fatty acids $(>10 \%)$ detected in strain $\mathrm{HM}_{134^{\mathrm{T}}}$ included iso- $\mathrm{C}_{16: 0}(30.3 \%)$, iso- $\mathrm{C}_{15: 0}(14.1 \%)$ and 10-methyl $\mathrm{C}_{18: 0}$ (TBSA, $12.4 \%$ ), consistent with the previous findings that iso- $\mathrm{C}_{16: 0}$ and iso- $\mathrm{C}_{15: 0}$ were the predominant cellular fatty acids of the genus Micromonospor ${ }^{33}$ and reference strains (Supplementary Table S2). The polar lipid profile of strain HM134 ${ }^{\mathrm{T}}$ comprised diphosphatidylglycerol (DPG), phosphatidylethanolamine (PE), an unidentified phospholipid (PL1), three unidentified glycolipids (GL1, GL2 and GL3) and two unidentified lipids (L1 and L2). DPG and PE were also detected in the three reference strains (Table 1) and other Micromonospora species. The presence of GL1-3 and the absence of PI, PIM and PS could differentiate strain $\mathrm{HM} 134^{\mathrm{T}}$ from the reference strains.

Phenotypic Characterization of the HM134 Isolate. Strain HM134 $4^{\mathrm{T}}$ grew well on ISP 1, ISP 2, ISP $3^{34}$ agars, tryptone soy agar and nutrient agar after $7-14$ days at $28^{\circ} \mathrm{C}$, moderately on ISP 4 , ISP $5^{34}$ and Streptomyces agar, and poor on ISP $7^{34}$ and calcium malate agar ${ }^{35}$. The colors and substrate mycelia were dependent on the culture medium used (Table 2). Aerial hyphae were absent and no soluble pigment was produced in any of the culture media. Morphological observation of strain $\mathrm{HM} 134^{\mathrm{T}}$ revealed that single spores were formed on the end of substrate hyphae (Supplementary Fig. S5). Growth was observed at pH 4.5-9.5 (optimum pH 5.5-8.5), with 0-7\% $\mathrm{NaCl}$ tolerance (optimum $0-1 \%$ ) and at $14-37^{\circ} \mathrm{C}$ (optimum $20-28^{\circ} \mathrm{C}$ ). Nitrate was weakly reduced to nitrite but not to $\mathrm{N}_{2}$. Cells were found to be positive for catalase but negative for melanoid pigment production. Liquefaction of gelatin, milk coagulation, hydrolysis of esculin and soluble starch were found to be positive, but negative for hydrolysis of cellulose, $\mathrm{H}_{2} \mathrm{~S}$ production, Voges-Proskauer test and methyl red test. According to Table 1 , strain $\mathrm{HM} 134^{\mathrm{T}}$ and all the reference strains could hydrolyze esclin and gelatin, utilize $\mathrm{N}$-acetyl-glucosamine and potassium gluconate, meanwhile esterase (C4) in strain $\mathrm{HM} 134^{\mathrm{T}}$ is weakly positive, which could be distinguished from other reference strains. Also the ability to hydrolyze starch revealed discrepancy between strain HM134 ${ }^{\mathrm{T}}$ and the most close strain M. rifamycinica AM105 ${ }^{\mathrm{T}}$. In addition, thirteen strains were chosen as representatives of adjacent clusters, the phenotypic characteristics were collected from literatures and compared with strain HM134 ${ }^{\mathrm{T}}$ (See Supplementary Table S3). The detailed physiological and biochemical properties are presented in the species description. 


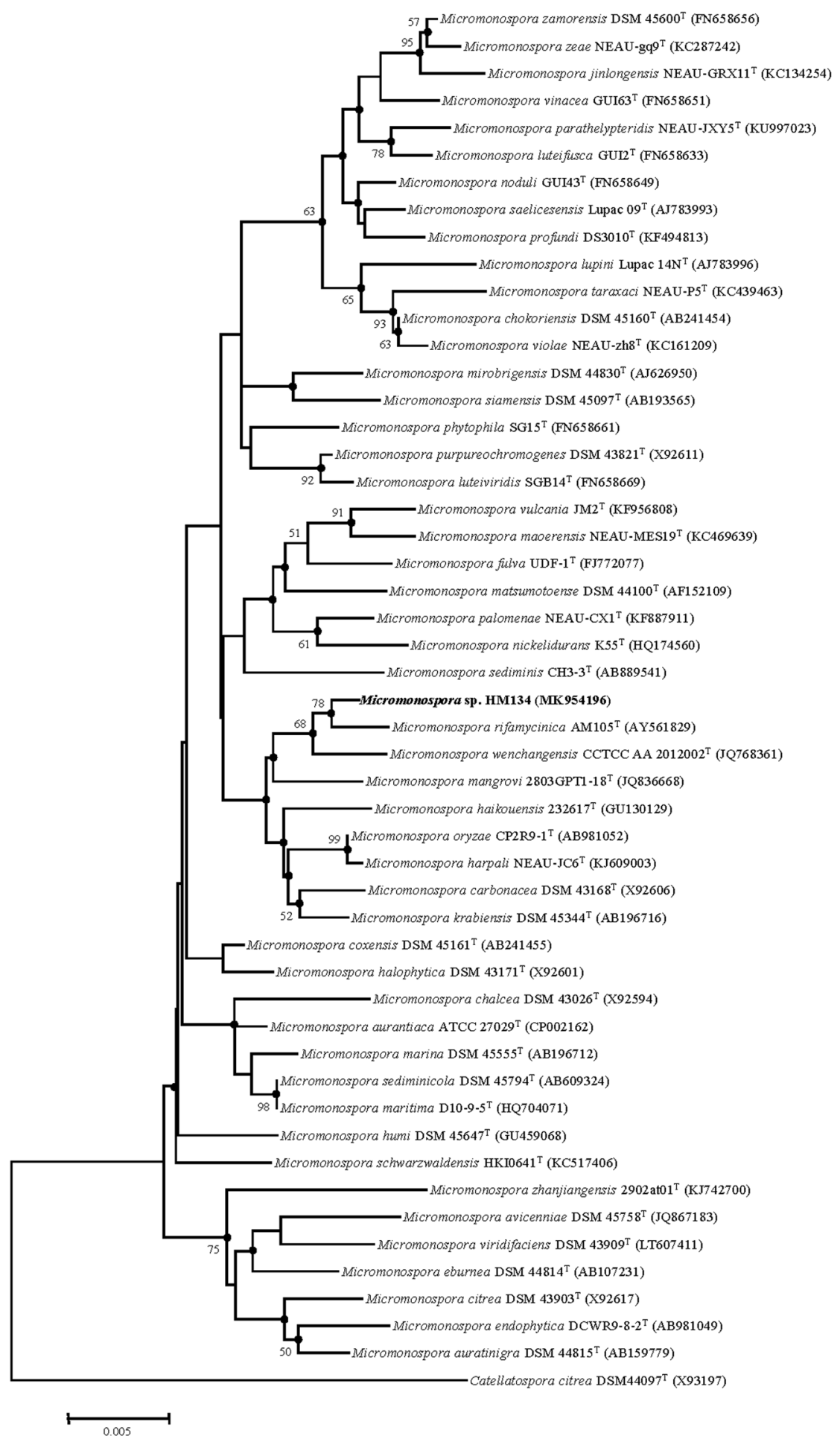

Figure 1. Neighbor-joining phylogenetic tree using the Kimura two-parameter model based on the 16S rRNA gene sequences of strain $\mathrm{HM} 134^{\mathrm{T}}$ and representatives of related taxa. Bootstrap values are based on 1000 replicates; values above $50 \%$ are shown. Filled circles indicate nodes also obtained in the maximum-likelihood and maximum-parsimony trees. Bar, 0.005 substitutions per nucleotide position.

Cytotoxic activity of strain $\mathrm{HM} 34^{\mathrm{T}}$ extract. The cytotoxic potential of $\mathrm{HM} 134^{\mathrm{T}}$ extract was tested against several human-derived cancer cell lines (HCT-116, HepG2 and A549) and the results are summarized in Fig. 3. All cancer cell lines showed susceptibility to the extract of stain HM134 ${ }^{\mathrm{T}}$ with inhibition ratios range from $88.84-98.5 \%(100 \mu \mathrm{g} / \mathrm{mL}$ extract was tested). The extract exhibited the highest toxicity against HCT-116 cells with the inhibition ratios of $98.50 \pm 4.8 \%$ and $48.73 \pm 2.5 \%$ when tested at the concentration of $100 \mu \mathrm{g} / \mathrm{mL}$ and $20 \mu \mathrm{g} / \mathrm{mL}$, respectively. As indicated, the inhibition ratio of A549 was significantly reduced at lower extract 


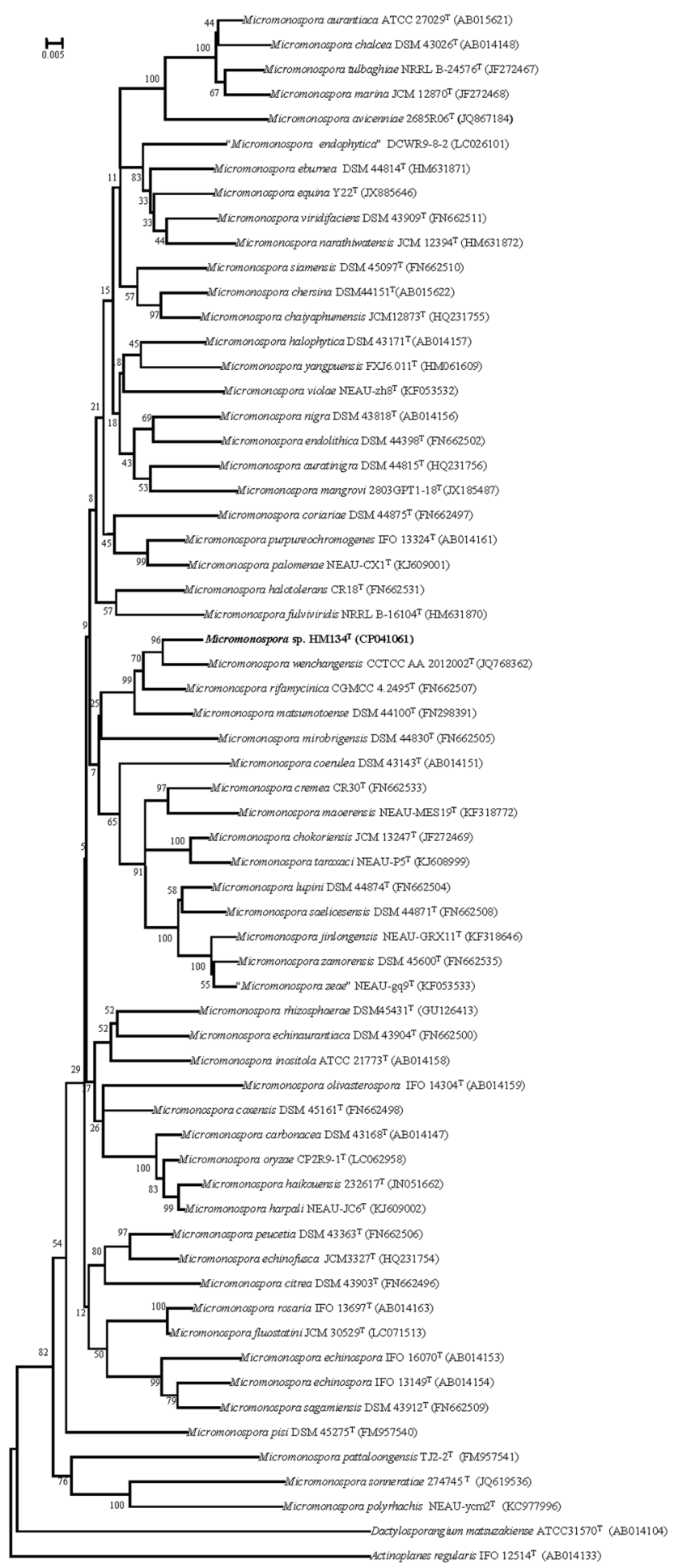

Figure 2. Neighbor-joining phylogenetic tree based on the partial gyrB gene sequences of strain $\mathrm{HM} 134^{\mathrm{T}}$ and representatives of related taxa. Bootstrap values are based on 1000 replicates; values above $50 \%$ are shown. Bar, 0.005 substitutions per nucleotide position.

concentration (decreased to $14.94 \pm 2.3 \%$ ). The correspongding inhibition ratios on HepG2 cells were 95.34 $\pm 5.7 \%$ and $26.84 \pm 4.2 \%$, respectively. Furthermore, we observed a dose-dependent effect when the extract was tested against human-derived cancer cell lines. Overall, the results suggested that the HM134 ${ }^{\mathrm{T}}$ extract has a higher cytotoxic effect against the HCT-116 cell lines than the HepG2 and A549 cell lines. Based on the results of the cytotoxicity, we further characterized the bioactive metabolites of strain HM134 ${ }^{\mathrm{T}}$ against HCT-116, HepG2 and A549 cells. 


\begin{tabular}{|c|c|c|c|c|}
\hline Characteristic & 1 & 2 & 3 & 4 \\
\hline Temperature for growth $\left({ }^{\circ} \mathrm{C}\right)$ & $14-37$ & $20-37^{a}$ & $16-45^{\mathrm{b}}$ & $16-42^{c}$ \\
\hline $\mathrm{pH}$ range for growth & $4.5-9.5$ & $6-8^{b}$ & $5-9^{\mathrm{b}}$ & $5.5-8^{c}$ \\
\hline $\mathrm{NaCl}$ tolerance $(\%)$ & 7 & $4^{\mathrm{b}}$ & $3^{\mathrm{b}}$ & $3^{c}$ \\
\hline Nitrate reduced to nitrite & - & - & - & + \\
\hline Gelatin liquefaction & + & + & + & - \\
\hline Glucose fermentation & w & + & - & $\mathrm{w}$ \\
\hline \multicolumn{5}{|l|}{ Enzyme activity } \\
\hline Alkaline phosphatase & + & + & $\mathrm{w}$ & + \\
\hline$\alpha$-chymotrypsin & - & - & $\mathrm{w}$ & + \\
\hline Esterase $(\mathrm{C} 4)$ & $\mathrm{w}$ & - & - & - \\
\hline Esterase lipase(C8) & $\mathrm{w}$ & $\mathrm{w}$ & - & - \\
\hline$\alpha$-galactosidase & - & - & - & $\mathrm{w}$ \\
\hline$\beta$-glucosidase & w & + & w & w \\
\hline Lipase(C14) & - & - & + & - \\
\hline Naphthol AS-BI phosphohydrolase & - & - & - & w \\
\hline $\mathrm{N}$-acetyl- $\beta$-glucosaminidase & - & - & $\mathrm{w}$ & + \\
\hline Urease & w & $\mathrm{w}$ & $\mathrm{w}$ & - \\
\hline Valin arylamidase & $\mathrm{w}$ & - & $\mathrm{w}$ & - \\
\hline \multicolumn{5}{|l|}{ Hydrolysis of: } \\
\hline Starch & + & - & + & $\mathrm{w}$ \\
\hline Tween 20 & - & - & + & + \\
\hline Tween 60 & + & $\mathrm{w}$ & + & + \\
\hline Tween 80 & - & - & + & - \\
\hline Esculin & + & + & + & $\mathrm{w}$ \\
\hline \multicolumn{5}{|l|}{ Utilization of: } \\
\hline N-Acetyl-glucosamine & $\mathrm{w}$ & + & $\mathrm{w}$ & $\mathrm{w}$ \\
\hline D-Mannitol & $\mathrm{w}$ & + & - & $\mathrm{w}$ \\
\hline Potassium gluconate & + & + & $\mathrm{w}$ & + \\
\hline Malic acid & $\mathrm{w}$ & + & - & + \\
\hline Major Polar Lipids & PE, DPG & PE, DPG, PIM, PS ${ }^{c}$ & PE, DPG, PI, PIM ${ }^{b}$ & $\mathrm{PE}, \mathrm{DPG}, \mathrm{PI}^{\mathrm{c}}$ \\
\hline Major menaquinones & MK-10(H6) & $\begin{array}{l}\text { MK-10(H6), MK- } \\
10(\mathrm{H} 4), \mathrm{MK}-9(\mathrm{H} 4)^{\mathrm{d}}\end{array}$ & MK-10(H6), MK-9(H6) & $\begin{array}{l}\text { MK-10(H6), MK-9(H6), } \\
\text { MK-9(H4) }\end{array}$ \\
\hline DNA G+C content (mol\%) & 73.2 & $71.0^{\mathrm{a}}$ & $71.7^{\mathrm{b}}$ & $71.2^{\mathrm{c}}$ \\
\hline
\end{tabular}

Table 1. Differential phenotypic characteristics of strain $\mathrm{HM} 134^{\mathrm{T}}$ and the type strains of related species Strains: Strains: 1, HM134 ${ }^{\mathrm{T}} ; 2$, M. rifamycinica AM105 ${ }^{\mathrm{T}}$; 3, M. wenchangensis CCTCC AA $2012002^{\mathrm{T}}$; 4, M. mangrovi $2803 \mathrm{GPT} 1-18^{\mathrm{T}}$. All data are obtained from this study unless otherwise indicated. + , Positive; - , negative; $\mathrm{w}$, weakly positive. a: ${ }^{79} \cdot \mathrm{b}::^{80} \cdot \mathrm{c}^{21} \cdot \mathrm{d}:{ }^{16}$.

\begin{tabular}{|l|l|l|l|l|}
\hline Medium & Growth & Color of colony & $\begin{array}{l}\text { Diffused } \\
\text { pigment }\end{array}$ & $\begin{array}{l}\text { Colony } \\
\text { surface }\end{array}$ \\
\hline ISP1 & Abundant & Beige & None & Rough \\
\hline ISP2 & Abundant & Beige & None & Rough \\
\hline ISP3 & Abundant & Deep orange & None & Rough \\
\hline ISP4 & Moderate & Oyster white & None & Smooth \\
\hline ISP5 & Moderate & Oyster white & None & Smooth \\
\hline ISP7 & Poor & Ivory & None & Smooth \\
\hline Tryptone Soy agar & Abundant & Beige & None & Rough \\
\hline Streptomyces agar & Moderate & Oyster white & None & Smooth \\
\hline Calium Malate Agar & Poor & Oyster white & None & Smooth \\
\hline Nutrient Agar & Abundant & Pastel yellow & None & Rough \\
\hline
\end{tabular}

Table 2. Phenotypic characteristics of strain $\mathrm{HM} 134^{\mathrm{T}}$ on different mediums. All data were obtained from this study.

Identification of active compounds. Bioassay-guided isolation of the active components of HM134 $4^{\mathrm{T}}$ was carried out as described in the Materials and Methods. The active metabolite was characterized by spectroscopic analyses and by comparison with the data available from literature. This compound was obtained as a yellow 


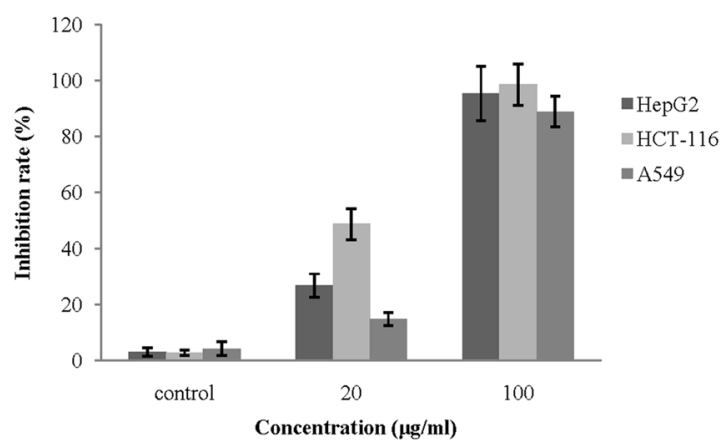

Figure 3. Cytotoxic activity of $\mathrm{HM} 134^{\mathrm{T}}$ extract against human cancer cell lines. The measurement of inhibition rate was done using CCK-8 method. The graphs show cytotoxicity effect of HCT-116 HepG2 and A549. Medium containing $0.5 \%$ dimethyl sulfoxide was used as a control. All data are presented as the mean \pm standard deviation from three experiments.<smiles>[3H]C([3H])C1CCCC(=O)C1=CC1CCC=C(C(=O)O)C(O)C1/C=C/C(=O)OC</smiles>

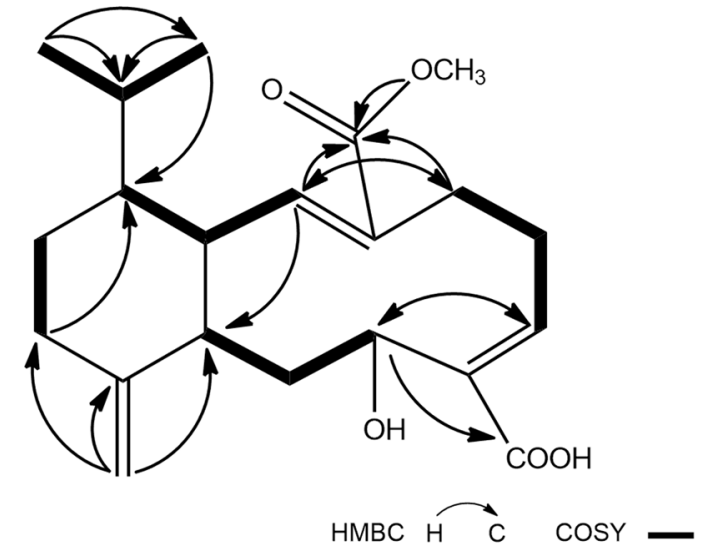

Figure 4. Structure of compounds 1 from strain $\mathrm{HM} 134^{\mathrm{T}}$.

amorphous gum. Its molecular formula, $\mathrm{C}_{21} \mathrm{H}_{30} \mathrm{O}_{5}$, was deduced from TOF-MS m/z 363.2182 [M+ H] ${ }^{+}$, which was consistent with the ${ }^{1} \mathrm{H}$ NMR and ${ }^{13} \mathrm{C}$ NMR data (See Supplementary Figs. S6-S13 and Table S4). As shown in Fig. 4, the structure of compound 1 displayed a novel diterpenoid derivative.

The IR spectrum showed characteristic absorptions for hydroxyl $\left(3659 \mathrm{~cm}^{-1}\right)$ and carbonyl $\left(1704 \mathrm{~cm}^{-1}\right)$. The ${ }^{1} \mathrm{H}$ NMR spectrum of compound 1 indicated the presence of two aliphatic methyl doublets at $\delta_{\mathrm{H}} 0.80(3 \mathrm{H}, \mathrm{d}, J=6.6 \mathrm{~Hz})$ and $0.83(3 \mathrm{H}, \mathrm{d}, J=6.6 \mathrm{~Hz})$, a methoxy at $\delta_{\mathrm{H}} 3.75(3 \mathrm{H}, \mathrm{s})$, an oxygenated methane proton at $\delta_{\mathrm{H}} 4.11(1 \mathrm{H}$, dd, $J=10.6$, $4.6 \mathrm{~Hz})$, one olefinic methylene at $\delta_{\mathrm{H}} 4.64(1 \mathrm{H}, \mathrm{br} \mathrm{s}), 4.69(1 \mathrm{H}, \mathrm{br} \mathrm{s})$, and two olefinic methines at $\delta_{\mathrm{H}} 6.35(1 \mathrm{H}, \mathrm{t}$, $J=8.5 \mathrm{~Hz}), 6.91(1 \mathrm{H}, \mathrm{d}, J=12.4 \mathrm{~Hz})$. The ${ }^{13} \mathrm{C}$ NMR and HSQC spectra exhibited 21 carbon resonances, comprising two carboxyls $\left(\delta_{\mathrm{C}} 168.6,170.0\right)$, three olefinic quaternary carbons $\left(\delta_{\mathrm{C}} 128.4,131.4,150.0\right)$, two olefinic methines $\left(\delta_{\mathrm{C}}\right.$ $145.4,145.4)$, one olefinic methylene $\left(\delta_{\mathrm{C}} 109.2\right)$, one oxygenated methine $\left(\delta_{\mathrm{C}} 78.7\right)$, four methines $\left(\delta_{\mathrm{C}} 30.9,41.8\right.$, $42.5,46.5)$, five methylenes $\left(\delta_{\mathrm{C}} 26.0,26.9,28.1,33.0,39.3\right)$, a methoxy $\left(\delta_{\mathrm{C}} 51.8\right)$, and two methyls $\left(\delta_{\mathrm{C}} 21.0,21.5\right)$. Detailed analysis of the ${ }^{1} \mathrm{H}-{ }^{1} \mathrm{H}$ COSY and $\mathrm{HMBC}$ correlations (Fig. 4) established the structure of compound 1. 


\begin{tabular}{|l|l|}
\hline Attribute & Value \\
\hline Size (bp) & $7,565,212$ \\
\hline DNA G+C content (\%) & 73.2 \\
\hline CDSs & 6853 \\
\hline CDSs assigned to COGs (percentages) & $4688(68.4)$ \\
\hline CDSs assigned to KEGG (percentages) & $3061(44.7)$ \\
\hline CDSs assigned to GO (percentages) & $3710(54.1)$ \\
\hline rRNA operon (16S-5S-23S rRNA) & 12 \\
\hline tRNAs & 53 \\
\hline CRISPR repeats & 3 \\
\hline
\end{tabular}

Table 3. General features of the genome of Micromonospora sp. HM134.

An isopropyl moiety was established by the ${ }^{1} \mathrm{H}-{ }^{1} \mathrm{H}$ COSY correlations of $\mathrm{H}_{3}-16 / \mathrm{H}-15 / \mathrm{H}_{3}-17$ and the $\mathrm{HMBC}$ correlations from $\mathrm{H}_{3}-16$ to $\mathrm{C}-15$ and $\mathrm{C}-17$, from $\mathrm{H}_{3}-17$ to $\mathrm{C}-15$ and $\mathrm{C}-16$. Furthermore, ${ }^{1} \mathrm{H}^{-1} \mathrm{H}$ COSY correlations of $\mathrm{H}-1 / \mathrm{H}-2 / \mathrm{H}-3, \mathrm{H}_{2}-5 / \mathrm{H}_{2}-6 / \mathrm{H}-7, \mathrm{H}-9 / \mathrm{H}_{2}-10 / \mathrm{H}-11$ and $\mathrm{H}_{2}-13 / \mathrm{H}_{2}-14$ indicated the four structural moieties of C-1-C3, C-5-C-7, C-9-C-11 and C-13-C-14. The HMBC correlations from $\mathrm{H}_{2}-20$ to C-11, C-12 and C-13 revealed the connection of C-11 and C-13 through C-12. The linkage of C-1 and C-14 was confirmed by the HMBC signal from $\mathrm{H}_{2}-13$ to $\mathrm{C}-1$. The HMBC correlation of $\mathrm{H}-3$ and C-11 established the connection of C-2 and C-11.The observed ${ }^{1} \mathrm{H}-{ }^{13} \mathrm{C}$ long-range correlations from $\mathrm{H}-7$ to $\mathrm{C}-9, \mathrm{C}-21$ and from $\mathrm{H}-9$ to $\mathrm{C}-7$ and $\mathrm{C}-21$ showed that C-7 and C-9 was connected through C-8 and a carboxyl group was situated at C-8. Similarly, HMBC correlations from H-3 to C-5 and $\mathrm{C}-18$, from $\mathrm{H}_{2}-5$ to $\mathrm{C}-3$ and $\mathrm{C}-18$, from $\mathrm{H}_{3}-19$ to $\mathrm{C}-18$ indicated that $\mathrm{C}-3$ and $\mathrm{C}-5$ was connected via $\mathrm{C}-4$ and one acetate was attached to $\mathrm{C}-4$. As a result, the structure of the compound was shown in Fig. 4. According to the NOESY data (See Supplementary Fig. S14), the correlation of $\mathrm{H}-2 / \mathrm{H}-5$ and $\mathrm{H}-7 / \mathrm{H}-10$ revealed that both the double bonds could be assigned to be of E-configuration. Compound 1 was named as (7E,11E)-6-hydroxy-1-isopropyl-11(methoxycarbonyl)-4-methylene-1,2,3,4,4a,5,6,9,10,12a-decahydrobenzo[10] annulene-7-carboxylic acid.

Cytotoxicity of bioactive metabolite from Strain $\mathrm{HM} 134^{\top}$. The cytotoxic activities of compound 1 against the HepG2, HCT-116 and A549 human cancer cell lines were measured. It suppressed the proliferation of HepG2, HCT-116 and A549 cancer cells. This compound exhibited the strongest cytotoxicity against HCT-116 cells, with the $\mathrm{IC}_{50}$ value of $38.4 \mu \mathrm{g} / \mathrm{mL}$. Meanwhile, it also exhibited moderate cytotoxicity against HepG2 cells and $\mathrm{A} 549$ cells, with $\mathrm{IC}_{50}$ values of 69.8 and $50.5 \mu \mathrm{g} / \mathrm{mL}$, respectively.

Genotypic characterization of the $\mathrm{HM} 134^{\mathrm{T}}$ isolate and screening for antibiotic biosynthetic gene clusters. The genome of strain $\mathrm{HM} 134^{\mathrm{T}}$ consists of one circular chromosome $(7,565,212 \mathrm{bp}, 73.2 \%$ $\mathrm{G}+\mathrm{C}$ ), with the absence of plasmid. A total of 6853 protein-coding sequences (CDS) and 109 RNA genes were predicted. The genomic features of strain $\mathrm{HM} 134^{\mathrm{T}}$ were summarized in Table 3.

Among the 6853 CDSs, only 4688 CDSs were classified into COG categories (See Supplementary Table S5). The major categories included transcription $(9.8 \%)$, carbonhydrate and amino acid transport and metabolism (8.2\% and 7.7\%, respectively), signal transduction mechanisms $(5.9 \%)$, coenzyme, lipid and inorganic ion transport and metabolism $(5.7 \%, 5.6 \%$ and $5.4 \%$ respectively). Noteworthy, the poorly characterized category General function prediction only (11.85\%) included many secondary metabolites synthesis clusters, indicating that there were lots of functional genes were unclear in strain $\mathrm{HM}_{134^{\mathrm{T}}}^{\mathrm{T}}$. A total of 32 secondary metabolite gene clusters were detected using antiSMASH. There were 4 terpene clusters, 2 type I PKS clusters, 1 type II PKS cluster, 1 type III PKS cluster, 5 NRPS clusters, 1 siderophore, 3 bacteriocins and 11 heterozygous PKS-NRPS clusters found in strain $\mathrm{HM} 134^{\mathrm{T}}$. These results highlighted the genomic potential of the inspected isolates for natural products discovery. Furthermore, the presence of terpene clusters is primarily responsible for the synthesis of the newly terpene derivate.

\section{Discussion}

Based on the polyphasic approach analysis, strain $\mathrm{HM} 134^{\mathrm{T}}$ was markedly different from the most closely related type strains of the genus Micromonospora. Therefore, strain $\mathrm{HM} 134^{\mathrm{T}}$ merits assignment to a novel species in the genus Micromonospora, for which the name M. zhangzhouensis sp. nov. is proposed. The type strain is $\mathrm{HM} 134^{\mathrm{T}}$.

The extract from strain HM134 ${ }^{\mathrm{T}}$ demonstrated $88.8-98.5 \%$ inhibition ratio against human cancer cell lines (HepG2, HCT-116 and A549) when tested at a concentration at $100 \mu \mathrm{g} / \mathrm{mL}$. Since the strain $\mathrm{HM} 134^{\mathrm{T}}$ is a novel Micromonospora species, it would be a potential reservoir of natural products with cytotoxic activity. Bioassay-guided separation and purification by multiple methods were successfully applied to identify the active fractions. The active compound $\mathbf{1}$ identified as a novel diterpenoid derivative that exhibited cytotoxic activity against cancer cells.

Terpenes are one of the major secondary metabolites with different compound types, including monoterpenenes, diterpenes, sesquiterpenes, triterpenes, sesterterpenes and norterpenes ${ }^{36,37}$. Although actinomycetes harbor the genetic potential to produce terpenes, terpenoid natural products are rarely observed when cultured in fermentation broths. The carbon skeleton of compound $\mathbf{1}$ is similar to cembrane-type diterpenoids, which form a large and structurally different group of natural products that can be isolated from both terrestrial and marine organisms. Cyclisation of a geranylgeraniol derived precursor between carbon 1 and 14 generates a 14-membered diterpenoid, named cembrane or thumbergane ${ }^{38}$. As previously reported, coelenterates are recognized as the 
most prominent source of cembranoids $s^{39,40}$. From a biomedical perspective, cytotoxicity is the most remarkable characteristic of cembranoids. In addition, cembranoids possess multiple biological activities such as neuroprotective, anti-inflammatory, antimicrobial, antiarthritic effects. In previous study, Luo, et al. ${ }^{41}$ reported that eight cembrane-type diterpenoids were isolated from Macaranga pustulat, a including three new compounds that exert cytotoxicity $\left(\mathrm{IC}_{50}>20 \mu \mathrm{M}\right)$ towards human cancer cell lines (CNE1, CNE2 and HCT116). In another study, researchers isolated two new cembrane diterpenes from the flowers of Nicotiana tabacum L. with anti-tumor activities against human tumor cell lines (HepG2, A549 and HCT-116) ${ }^{42}$. In addition, four unknown cembrane-type diterpenoids exhibiting hepatoprotective activity at $10 \mu \mathrm{M}$ against paracetamol-induced HepG2 cell damage were isolated from the gum resin of Boswellia sacra Flueck ${ }^{43}$. Another similar skeleton structure of compound 1 is cladiellane-type diterpenoid, one of the class of metabolites from gorgonians with the skeletons containing an ether bridge across C-2 and C- $9^{44}$. These metabolites also displayed a wide range of bioactivities. For example, $\mathrm{Ru}$, et $a l .{ }^{45}$ reported three cladiellane-type diterpenoids exhibiting moderate anti-inflammatory activity with the $\mathrm{IC}_{50}$ values range from 15.8 to $43.7 \mu \mathrm{M}$. Previous studies demonstrated that hydroxylated derivatives showed improved anti-cancer activity ${ }^{46}$, suggesting that the hydroxyl group of compound 1 may contribute to the suppressive effect on human cancer cells.

In summary, the strain HM134 ${ }^{\mathrm{T}}$, a novel species of the genus Micromonospora was successfully isolated from the mangrove soil of Zhangzhou, China. The findings of this study demonstrated that the strain HM134 exhibited significant cytotoxic activity against human cancer cell lines (HepG2, HCT-116 and A549) and a new diterpenoid derivative was found. This study provides a comprehensive description of the novel strain Micromonospora zhangzhouensis $\mathrm{HM} 134^{\mathrm{T}}$ and elucidated the potential of the strain as a resource for anticancer or drug discovery. Hence, further studies to provide in-depth research on the cytotoxic property of this strain are highly valuable.

Description of Micromonospora sp. nov. Zhangzhouensis (zhang.zhou.en'sis. N.L. fem. adj. zhangzhouensis referring to Zhangzhou, a city in Fujian, China, from where the type strain was isolated).

Cells are gram-positive, non-motile, actinomycete that forms well-developed and branched substrate hyphae. Oval spores are smooth-surfaced with the size of $0.6 \times 0.8 \mu \mathrm{m}$. Colonies range from pastel orange to beige in corlor when cultured on ISP 2 medium. The colors of the substrate mycelia are dependent on the culture medium. Aerial hyphae were absent and no soluble pigment was produced in any of the culture media. Cells grow well on ISP 1, ISP 2, ISP 3 agars, tryptone soy agar and nutrient agar after $7-14$ days at $28^{\circ} \mathrm{C}$, moderately on ISP 4 , ISP 5 and Streptomyces agars, poorly on ISP 7 and calcium malate agar. Growth was observed at pH 4.5-9.5 (optimum $\mathrm{pH} 5.5-8.5$ ), with $0-7 \%(\mathrm{w} / \mathrm{v}) \mathrm{NaCl}$ tolerance (optimum $0-1 \%$ ) and at $14-37^{\circ} \mathrm{C}$ (optimum $20-28^{\circ} \mathrm{C}$ ). Nitrate was weakly reduced to nitrite. Nitrite was not reduced to $\mathrm{N}_{2}$. Cells were positive for catalase, alkaline phosphatase, acid phosphatase, $\beta$-galactosidase, $\alpha$-glucosidase, leucine arylamidase, PNPG and trypsin. Weakly for arginine dihydrolase, esterase (C4), esterase lipase (C8), $\beta$-glucosidase and valine arylamidase. Negative for $\alpha$-chymotrypsin, arginine dihydrolase, cystine arylamidase, $\alpha$-fucosidase, $\alpha$-galactosidase, $\beta$-glucuronidase, $\alpha$-mannosidase, lipase (C14), napthol-AS-BI-phosphohydrolase and N-acetyl- $\beta$-glucosaminidase. Positive for liquefaction of gelatin, milk coagulation, hydrolysis of esculin and soluble starch, degradation of Tween 40 and Tween 60 . Weakly for glucose fermentation. Negative for hydrolysis of cellulose, production of $\mathrm{H}_{2} \mathrm{~S}$, Voges-Proskauer test, methyl red test, degradation of Tween 20, Tween 80 , adenine, guanine, xanthine and hypoxanthine. Positive for utilization of L-arabinose, D-glucose, maltose, D-mannose, potassium gluconate and adipic acid. Weakly utilize $\mathrm{N}$-acetyl-b-glucosaminidase and D-mannitol, malic acid. Do not utilize n-capiric acid, citrate, phenylacetic acid or tryptophan. The major fatty acids $(>10 \%)$ were iso- $\mathrm{C}_{16: 0}(30.3 \%)$, iso- $\mathrm{C}_{15: 0}(14.1 \%)$ and 10-methyl $\mathrm{C}_{18: 0}$ (TBSA, 12.4\%). The polar lipid profile of strain $\mathrm{HM} 134^{\mathrm{T}}$ comprised diphosphatidylglycerol, phosphatidylethanolamine, an unidentified phospholipid, three unidentified glycolipids and two unidentified lipids. The major respiratory quinine was MK-10(H6). The cell wall of strain HM134 ${ }^{\mathrm{T}}$ contained meso-DAP. Whole-cell hydrolysates predominantly contained xylose, arabinose and glucose. The type strain $\mathrm{HM} 134^{\mathrm{T}}$, was isolated from the rhizosphere soil of the mangrove in Fujian, China. The GenBank accession number for the 16S rRNA gene sequence and the genome sequence of strain HM134 ${ }^{\mathrm{T}}$ is MK954196 and CP041061, respectively. The DNA G + C content of the type strain was determined to be $73.2 \mathrm{~mol} \%$ (in silico).

\section{Materials and Methods}

Sample collection and isolation of actinomycetes. Strain $\mathrm{HM} 134^{\mathrm{T}}$ was isolated from a soil sample collected in the mangrove Avicennia marina forest of Zhangzhou (N24 $40^{\prime}$, E118 $11^{\prime}$ ), Fujian Province (China) during the spring of 2015 and subsequently stored at $4{ }^{\circ} \mathrm{C}$ until use. The soil sample was suspended in sterile water and diluted in a tenfold series. The dilutions were then spread onto modified Gauze's No.1 agar ${ }^{47}$ supplemented with nystatin $(50 \mu \mathrm{g} / \mathrm{ml})$ and nalidixic acid $(25 \mu \mathrm{g} / \mathrm{ml})$ incubated at $28^{\circ} \mathrm{C}$ for 14 days. After incubation, a yellow colony was selected and purified by repeated streaking on to Gauze's No.1 agar. The strain was routinely cultured in Gauze's No.1 agar and preserved as glycerol suspensions $(20 \%, \mathrm{v} / \mathrm{v})$ at $-20^{\circ} \mathrm{C}$.

DNA extraction and purification. Genomic DNA was extracted using a Quick Bacteria Genomic DNA Extraction kit (DongSheng Biotech). The 16S rRNA gene of strain HM134 ${ }^{\mathrm{T}}$ was amplified using the universal primers $27 \mathrm{~F}$ (5'-AGAGTTTGATCMTGGCTCAG-3') and $1492 \mathrm{R}$ (5'-TACGGYTACCTTGTTACGACTT $\left.-3^{\prime}\right)^{48}$. The amplification products were cloned into the pMD19-T vector (TaKaRa) and then sequenced. The obtained 16S rRNA gene sequence (1480 nt) was analyzed by performing pairwise sequence alignments using the NCBI nr database (http://www.ncbi.nlm.nih.gov) and the EzTaxon-e server (https://www.ezbiocloud.net) ${ }^{49}$. Multiple sequence alignments based on the $16 \mathrm{~S}$ rRNA gene sequences of strain $\mathrm{HM} 134^{\mathrm{T}}$ and related taxa were performed using the CLUSTAL X program of the MEGA 5 software package s $^{50}$. Phylogenetic trees were reconstructed from 1000 replicates using the neighbor-joining ${ }^{51}$, maximum-likelihood ${ }^{52}$ and maximum-parsimony ${ }^{53}$ 
methods based on 1000 replications and bootstrap analysis. To testify the phylogenetic tree reconstructed by MEGA 5, All-Species Living Tree LTPs123 and database arb-6.0.6 were used as the reference, SINA webserver ${ }^{54}$ and ARB software ${ }^{55}$ were used for alignment of $16 \mathrm{~S}$ rRNA gene sequence into LTPs123 and generation of a new maximum-likehood phylogenetic tree, respectively.

The complete genome was sequenced at the Beijing Genome Institute (BGI, Shenzhen, China) using a PacBio RS II platform and Illumina HiSeq. 4000 platformand. The genome was assembled as described previously ${ }^{56}$. The DNA G + C content was determined by Rapid Annotation System Technology (RAST) ${ }^{57}$. The genome sequences of ten reference strains were retrieved from the GenBank database (Project accession numbers were listed in Supplementary Table S1). The average nucleotide identity (ANI) was calculated using the OrthoANI algorithm of the Chun lab's online Average Nucleotide Identity calculator ${ }^{58}$. The in silico dDDH value was calculated using the GGDC web server ${ }^{59}$ available at https://ggdc.dsmz.de/ggdc.php\#. Glimmer version 3.02 (Delcher et al., 2007) was used to predict open reading frames (ORFs) according to the manufacturers' instructions. Following this, ORFs were annotated using the NCBI NR, SwissProt ${ }^{60}, \mathrm{KEGG}^{61}, \mathrm{GO}^{62}$ and $\mathrm{COG}^{63}$ databases. The tRNA and rRNA genes were predicted using tRNAscan-SE ${ }^{64}$ and RNAmmer ${ }^{65}$, respectively. CRISPR repeats were predicted using CRISPR finder ${ }^{66}$. Biosynthetic gene clusters of secondary metabolites were predicted using the antiSMASH 3.0 web server ${ }^{67}$. The gene sequence of $g y r \mathrm{~B}$ was identified by RAST of the genome sequence of strain HM134 ${ }^{\mathrm{T}}$. The phylogenetic tree based on the housekeep gene $(g y r \mathrm{~B})$ of strain $\mathrm{HM} 134^{\mathrm{T}}$ and other strains was constructed using neighbor-joining method, with the Tamura-3-parameter model and G substitutions. M. rifamycinica AM105 ${ }^{\mathrm{T}}$, M. wenchangensis CCTCC AA $2012002^{\mathrm{T}}$ and M. mangrovi $2803 \mathrm{GPT} 1-18^{\mathrm{T}}$ were obtained from CGMCC (China General Microbiological Culture Collection Center,) and CCTCC (China Center for Type Culture Collection). Unless otherwise stated, all strains were incubated in TSB at $28^{\circ} \mathrm{C}$.

Phenotypic characterization of the $\mathrm{HM} 134^{\top}$ Isolate. The temperature range for growth was determined in ISP2 $(\mathrm{pH} 7.0)$ at $4-45^{\circ} \mathrm{C}\left(4,10,15,20,28,30,35,37\right.$ and $\left.45^{\circ} \mathrm{C}\right)$. The tolerance to $\mathrm{NaCl}$ concentrations was tested in ISP2 (pH 7.0) with the concentrations of $\mathrm{NaCl}$ at $0-10.0 \%(\mathrm{w} / \mathrm{v})$, with an increment of $0.5 \%$. The $\mathrm{pH}$ range for growth was tested with an interval of $0.5 \mathrm{pH}$ unit, by supplementation of ISP 2 medium with $30 \mathrm{mM}$ buffering agents at $28^{\circ} \mathrm{C}: 2$ - $(\mathrm{N}$-morpholino) ethanesulfonic acid for $\mathrm{pH} 5.5-6.5,3-(\mathrm{N}$-morpholino) propanesulfonic acid for $\mathrm{pH}$ 6.5-8.0, tricine for $\mathrm{pH} 8.0-9.0$, and bis-Tris propane for $\mathrm{pH} 9.0-9.5$. The optimal growth was determined after 7 days of incubation, and the growth limits were determined after 14 days of incubation. HM134 $4^{\mathrm{T}}$ was incubated at $28^{\circ} \mathrm{C}$ for 21 days on ISP 2 medium, and cell morphology was examined and observed using an optical microscopy (BX40; Olympus) after Gram staining, a transmission electron microscopy $(80 \mathrm{kV}$, JEM-1230; Jeol) after uranyl acetate $(0.5 \%, \mathrm{w} / \mathrm{v})$ staining and a scan electron microscope $(3.0 \mathrm{kV}, \mathrm{SU} 8010$, Hitachi) after fixation by osmium tetroxide vapor $(4 \%, w / v)$. The culture characteristics were determined following growth on tryptone-yeast extract agar (ISP 1), yeast extract-malt extract agar (ISP 2), oatmeal agar (ISP 3), inorganic salts-starch agar (ISP 4), glycerol-asparagine agar (ISP 5), and tyrosine agar (ISP 7) agars ${ }^{34}$; Gauze’s No.1 agar, nutrient agar, tryptone soya agar ${ }^{68}$ and calcium malate $\operatorname{agar}^{35}$ for 14 days at $28^{\circ} \mathrm{C}$. The colors of substrate and aerial mycelia were determined based on comparison with the ISCC-NBS color system ${ }^{69}$. Catalase and oxidase activity were tested following the method described by Sun, et al.$^{70}$. Hydrolysis tests were performed with different substrates supplemented with gelatin, skimmed milk, starch (5g/L); CM-cellulose (2 g/L); Tweens 20, 40, 60 and $80(1 \%, \mathrm{v} / \mathrm{v})$ and adenine, guanine, xanthine and hypoxanthine $(0.5 \%, \mathrm{v} / \mathrm{v})$. Anaerobic growth was determined in an anaerobic system (Anaero Pack-Micro Aero, 2.5-L, MGC, Japan) on ISP 2 supplemented with various electron acceptors as described by Chen, et al. ${ }^{71}$. Nitrate reduction was tested according to the protocol of Dong and Cai ${ }^{72}$. The methyl red and Voges-Proskauer tests were examined as described by Lányi ${ }^{73}$. Other biochemical properties and enzyme activities were tested using API ZYM and API 20NE kits (bioMérieux) according to the manufacturer's instructions.

Chemotaxonomic characterization. Cells used for the analysis of fatty acids were harvested from the third quadrants of ISP 2 agar plates. Fatty acid methyl esters (FAMEs) were extracted as described by Kuykendall, et $a l .{ }^{74}$ and analyzed according to the instructions of the Microbial Identification System (MIDI; Microbial ID).

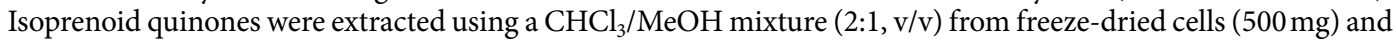
analyzed using an HPLC-MS system (Agilent) ${ }^{75}$. Polar lipids were extracted and separated by two-dimensional thin-layer chromatography on silica gel $60 \mathrm{~F}_{254}$ plates (Merck). Molybdophosphoric acid, ninhydrin reagent, molybdenum blue, and $\alpha$-naphthol $/ \mathrm{H}_{2} \mathrm{SO}_{4}$ reagents were used for the detection of total lipids, lipids containing free aminolipids, phosphorus-containing lipids and glycolipids, respectively ${ }^{76}$. The analyses of sugars and amino acids in whole cell hydrolysates were performed following previous methods ${ }^{77}$.

Preparation of the $\mathrm{HM} 134^{\mathrm{T}}$ fermented broth and extract. Strain $\mathrm{HM} 134^{\mathrm{T}}$ was inoculated into a 500 -mL Erlenmeyer flask containing $200 \mathrm{~mL}$ of GYM medium (containing malt extract $10.0 \mathrm{~g}$, yeast extract $4.0 \mathrm{~g}$, glucose $4.0 \mathrm{~g}, \mathrm{CoCl}_{2} \cdot 6 \mathrm{H}_{2} \mathrm{O} 0.005 \mathrm{~g}$ in $1.0 \mathrm{~L}$ tap water at $\mathrm{pH} 7.0-7.2$ ) as seed medium prior to fermentation process. Afterwards, $1 \%(\mathrm{v} / \mathrm{v})$ of the starting stock culture was transferred to a $1 \mathrm{~L}$ Erlenmeyer flask containing $25 \%$ volume of the fermentation medium and incubated at $28^{\circ} \mathrm{C}$ for 7 days on a rotary shaker at $250 \mathrm{rpm}$. The fermentation medium, H9A, consisted of soluble starch $20.0 \mathrm{~g}$, glucose $20.0 \mathrm{~g}$, soybean powder $10.0 \mathrm{~g}$, yeast extract $5.0 \mathrm{~g}$, malt extract $4.0 \mathrm{~g}, \mathrm{CaCO}_{3} 2.0 \mathrm{~g}, \mathrm{MgSO}_{4} \cdot 7 \mathrm{H}_{2} \mathrm{O} 2.0 \mathrm{~g}, \mathrm{NaCl} 3.0 \mathrm{~g}$, in 1.01 tap water at $\mathrm{pH} 7.0-7.2$. All culture media were sterilized at $121^{\circ} \mathrm{C}$ for $30 \mathrm{~min}$. The cell-free supernatant was collected by centrifugation at $4,000 \times \mathrm{rpm}$ for $10 \mathrm{~min}$ then subjected to freeze drying process. The freeze-dried sample was repeatedly extracted with methanol and the final extract concentrated using a rotary evaporator at $40^{\circ} \mathrm{C}$. The final concentrate was suspended in dimethyl sulfoxide prior to bioactivity assays. 
In vitro anti-tumor cytotoxicity. HCT-116 (humancolorectal carcinoma), A549 (human lung carcinoma) and HepG2 (human hepatocellular carcinoma) cell lines were obtained from the Department of New Drug Screening, Zhejiang Hisun Pharmaceutical Co., Ltd.(Taizhou, China). Cell lines were maintained in Dulbecco's modified Eagle's medium supplemented with $10 \%(\mathrm{w} / \mathrm{v})$ fetal bovine serum in a humidified incubator $\left(5 \% \mathrm{CO}_{2}\right.$ in air at $\left.37^{\circ} \mathrm{C}\right)$. The antitumor activities of different concentrations of HM134 $4^{\mathrm{T}}$ extracts $(20$ and $100 \mu \mathrm{g} / \mathrm{mL})$ were evaluated by the CCK- 8 colorimetric method. The cell lines were cultured in DMEM containing $10 \%$ calf serum at $37^{\circ} \mathrm{C}$ for $4 \mathrm{~h}$ in a $5 \% \mathrm{CO}_{2}$ incubator. The adherent cells in the logarithmic growth phase were digested and seeded on a 96 -well culture plate at a density of $1 \times 10^{4}$ cells per/well. Test samples and controls were added to the medium and incubated for $48 \mathrm{~h}$. Then, cell counting kit-8 (CCK-8, Dojindo) was added to the medium and incubated for $3 \mathrm{~h}$. Cell viability was determined by measuring the absorbance at $450 \mathrm{~nm}$ using a SpectraMax M5 microplate reader (Molecular Devices Inc., Sunnyvale, CA, USA) ${ }^{78}$. The inhibitory rate of cell proliferation was expressed as $\mathrm{IC}_{50}$ values. Doxorubicin was used as a positive control while cells containing 0.5\% DMSO were tested as negative control.

Isolation and characterization of bioactive metabolites. The cultivation procedure described in section Preparation of the HM134 $4^{\mathrm{T}}$ Fermented Broth and Extract was repeated and the filtrate $(30 \mathrm{~L})$ of the culture broth was collected. The filtrate was separated and purified in an HP-20 macroporous resin (Mitsubishi, Japan) column, and then eluted with absolute ethyl alcohol. After concentrating to dryness using a rotary evaporator at $40^{\circ} \mathrm{C}$, the residue $(30.0 \mathrm{~g})$ was resolved by chromatography on a silica gel column eluted with n-heptane/ethyl acetate mixtures that were run with a growing polarity (100:0 to 30:70, v/v) to obtain six fractions (Fr1-6). Results of bioactivity assays (in vitro antitumor toxicity) indicated that the Fr1 (n-heptane/ethyl acetate, 95:5) fractions was cytotoxic in vitro. The active fraction was repeatedly purified, and separated on Sephadex LH-20 gel column (GE Healthcare, Glies, UK). Semi-preparative HPLC (Shimadzu LC-8A, Shimadzu-C18, $5 \mu \mathrm{m}, 250 \times 20 \mathrm{~mm}$ Shimadzu, Kyoto, Japan) were performed to obtain compounds 1 ( $8.4 \mathrm{mg})$.

Structural identification of the bioactive metabolite was conducted by spectroscopic analysis. ${ }^{1} \mathrm{H}$ nuclear magnetic resonance (NMR) and ${ }^{13} \mathrm{C}$ NMR spectra were acquired using a Bruker DRX-400 spectrometer $(400 \mathrm{MHz}$ for ${ }^{1} \mathrm{H}$ and $100 \mathrm{MHz}$ for ${ }^{13} \mathrm{C}$ ) (Bruker, Rheinstetten, Germany). Chemical shifts were reported in ppm. ( $\delta$ ). Residual $\mathrm{CHCl}_{3}\left(\delta_{\mathrm{H}} 7.26 \mathrm{ppm} ; \delta_{\mathrm{C}} 77.0\right)$ was used as an internal standard, with coupling constants $(\mathrm{J})$ expressed in $\mathrm{Hz}$. ${ }^{1} \mathrm{H}$ and ${ }^{13} \mathrm{C}$ NMR assignments were supported by the results of the ${ }^{1} \mathrm{H}-1 \mathrm{H}$ COSY, HMQC, and HMBC experiments. The electrospray ionization MS data were recorded using a Time-of-Flight Mass Spectrometer X500R Q-TOF (Sciex, USA).

Received: 31 July 2019; Accepted: 13 February 2020;

Published online: 03 March 2020

\section{References}

1. Ørskov, J. Investigations into the Morphology of the Ray Fungi. (Levin and Munksgaard Publishers.; Copenhagen, 1923).

2. Kawamoto, I., Yamamoto, M. \& Nara, T. Micromonospora olivasterospora sp. nov. Int. J. Syst. Evol. Microbiol. 33, 107-112 (1983).

3. Hirsch, P., Mevs, U., Kroppenstedt, R. M., Schumann, P. \& Stackebrandt, E. Cryptoendolithic actinomycetes from Antarctic sandstone rock samples: Micromonospora endolithica sp. nov. and two isolates related to Micromonospora coerulea Jensen 1932. Syst. Appl. Microbiol. 27, 166-174 (2004).

4. Trujillo, M. E., Kroppenstedt, R. M., Fernandez-Molinero, C., Schumann, P. \& Martínez-Molina, E. Micromonospora lupini sp. nov. and Micromonospora saelicesensis sp. nov., isolated from root nodules of Lupinus angustifolius. Int. J. Syst. Evol. Microbiol. 57, 2799-2804 (2007).

5. Wang, C. et al. Micromonospora rhizosphaerae sp. nov., isolated from mangrove rhizosphere soil. Int. J. Syst. Evol. Microbiol. 61, 320-324 (2011).

6. Garcia, L. C., Martínez-Molina, E. \& Trujillo, M. E. Micromonospora pisi sp. nov., isolated from root nodules of Pisum sativum. Int. J. Syst. Evol. Microbiol. 60, 331-337 (2010).

7. Zhang, L., Xi, L., Ruan, J. \& Huang, Y. Micromonospora yangpuensis sp. nov., isolated from a sponge. Int. J. Syst. Evol. Microbiol. 62, 272-278, https://doi.org/10.1099/ijs.0.029439-0 (2012).

8. Kirby, B. M. \& Meyers, P. R. Micromonospora tulbaghiae sp. nov., isolated from the leaves of wild garlic, Tulbaghia violacea. Int. J. Syst. Evol. Microbiol. 60, 1328-1333 (2010).

9. Trujillo, M. E. et al. Micromonospora mirobrigensis sp. nov. Int. J. Syst. Evol. Microbiol. 55, 877-880, https://doi.org/10.1099/ ijs.0.63361-0 (2005)

10. Fang, B. et al. Two new species of the genus Micromonospora: Micromonospora palomenae sp. nov. and Micromonospora harpali sp. nov. isolated from the insects. Anton Leeuw 108, 141-150 (2015).

11. Berdy, J. Bioactive microbial metabolites. J. Antibiot. 58, 1 (2005).

12. Carro, L. et al. Genome-based classification of micromonosporae with a focus on their biotechnological and ecological potential. Sci. Rep. 8, 525 (2018).

13. Kathiresan, K. \& Bingham, B. L. Biology of mangroves and mangrove ecosystems (2001).

14. Azman, A.-S. et al Mangrove rare actinobacteria: taxonomy, natural compound, and discovery of bioactivity. Front Microbiol 6, https://doi.org/10.3389/fmicb.2015.00856 (2015).

15. Eccleston, G. P., Brooks, P. R. \& Kurtböke, D. I. The Occurrence of Bioactive Micromonosporae in Aquatic Habitats of the Sunshine Coast in Australia. Mar. Drugs 6, 243-261 (2008).

16. Xie, Q.-y., Qu, Z., Lin, H.-p., Li, L. \& Hong, K. Micromonospora haikouensis sp. nov., isolated from mangrove soil. Anton Leeuw 101, 649-655 (2012).

17. Zhang, L., Li, L., Deng, Z. \& Hong, K. Micromonospora zhanjiangensis sp. nov., isolated from mangrove forest soil. Int. J. Syst. Evol. Microbiol. 65, 4880-4885, https://doi.org/10.1099/ijsem.0.000667 (2015).

18. Phongsopitanun, W. et al. Micromonospora fluostatini sp. nov., isolated from marine sediment. Int. J. Syst. Evol. Microbiol. 65, 4417-4423, https://doi.org/10.1099/ijsem.0.000589 (2015).

19. Phongsopitanun, W. et al. Micromonospora sediminis sp. nov., isolated from mangrove sediment. Int. J. Syst. Evol. Microbiol. 66, 3235-3240, https://doi.org/10.1099/ijsem.0.001175 (2016).

20. Li, L. et al. Micromonospora sonneratiae sp. nov., isolated from a root of Sonneratia apetala. Int. J. Syst. Evol. Microbiol. 63, 2383-2388, https://doi.org/10.1099/ijs.0.043570-0 (2013). 
21. Xie, Q.-Y. et al. Micromonospora mangrovi sp. nov., isolated from mangrove soil. Anton Leeuw 109, 483-491, https://doi. org/10.1007/s10482-015-0641-x (2016).

22. Songsumanus, A., Tanasupawat, S., Igarashi, Y. \& Kudo, T. Micromonospora maritima sp. nov., isolated from mangrove soil. Int. J. Syst. Evol. Microbiol. 63, 554-559, https://doi.org/10.1099/ijs.0.039180-0 (2013).

23. Charan, R. D. et al. Diazepinomicin, a new antimicrobial alkaloid from a marine Micromonospora sp. J. Nat. Prod. 67, 1431-1433 (2004).

24. Yan, X. et al. Genome mining of Micromonospora yangpuensis DSM 45577 as a producer of an anthraquinone-fused enediyne. Org. Lett. 19, 6192-6195 (2017).

25. Kittiwongwattana, C. et al. Micromonospora oryzae sp. nov., isolated from roots of upland rice. Int. J. Syst. Evol. Microbiol. 65, 3818-3823, https://doi.org/10.1099/ijsem.0.000500 (2015).

26. Jongrungruangchok, S., Tanasupawat, S. \& Kudo, T. Micromonospora krabiensis sp. nov., isolated from marine soil in Thailand. J. Gen. Appl. Microbiology 54, 127-133, https://doi.org/10.2323/jgam.54.127 (2008).

27. Kasai, H., Tamura, T. \& Harayama, S. Intrageneric relationships among Micromonospora species deduced from gyrB-based phylogeny and DNA relatedness. Int. J. Syst. Evol. Microbiol. 50, 127-134 (2000).

28. Gurovic, M. S. V. et al. Micromonospora schwarzwaldensis sp. nov., a producer of telomycin, isolated from soil. Int. J. Syst. Evol. Microbiol. 63, 3812-3817, https://doi.org/10.1099/ijs.0.051623-0 (2013).

29. Supong, K. et al. Micromonosporasediminicola sp. nov., isolated from marine sediment. Int. J. Syst. Evol. Microbiol. 63, 570-575, https://doi.org/10.1099/ijs.0.041103-0 (2013).

30. Songsumanus, A., Tanasupawat, S., Thawai, C., Suwanborirux, K. \& Kudo, T. Micromonospora humi sp. nov., isolated from peat swamp forest soil. Int. J. Syst. Evol. Microbiol. 61, 1176-1181 (2011).

31. Carro, L. et al. Micromonospora phytophila sp. nov. and Micromonospora luteiviridis sp. nov., isolated as natural inhabitants of plant nodules. Int. J. Syst. Evol. Microbiol. 68, 248-253, https://doi.org/10.1099/ijsem.0.002490 (2018).

32. Mende, D. R., Sunagawa, S., Zeller, G. \& Bork, P. Accurate and universal delineation of prokaryotic species. Nat. methods 10, 881 (2013).

33. Thawai, C., Kanchanasin, P., Ohkuma, M., Kudo, T. \& Tanasupawat, S. Identification and antimicrobial activity of Micromonospora strains from Thai peat swamp forest soils. J. Appl. Pharm. Sci. 8, 119-125 (2018).

34. Shirling, E. B. \& Gottlieb, D. Methods for characterization of Streptomyces species. Int. J. Syst. Bacteriol. 16, 313-340 (1966).

35. Také, A., Inahashi, Y., Ōmura, S., Takahashi, Y. \& Matsumoto, A. Streptomyces boninensis sp. nov., isolated from soil from a limestone cave in the Ogasawara Islands. Int. J. Syst. Evol. Microbiol. 68, 1795-1799 (2018).

36. Yao, J.-L. et al. A review on the terpenes from genus Vitex. Molecules 21, 1179 (2016).

37. Murphy, R. B. Systems and methods for extraction of natural products. United States patent (2018).

38. Yang, B., Liu, J., Wang, J., Liao, S. \& Liu, Y. In Handbook of Anticancer Drugs from Marine Origin (ed Se-Kwon Kim) 649-672 (Springer International Publishing, 2015).

39. Qin, S., Huang, H. \& Guo, Y.-W. A new cembranoid from the Hainan soft coral Sinularia sp. J. Asian Nat. Prod. Res. 10, 1075-1079, https://doi.org/10.1080/10286020802319410 (2008).

40. Lin, Y.-S. et al. Cembrane diterpenoids from the Taiwanese soft coral Sinularia flexibilis. Tetrahedron 65, 9157-9164, https://doi. org/10.1016/j.tet.2009.09.031 (2009).

41. Luo, P. et al. Cembrane-type diterpenoids from Macaranga pustulata. Fitoterapia 129, 162-166, https://doi.org/10.1016/j. fitote.2018.06.020 (2018).

42. He, X.-F. et al. Two new cembranic diterpenoids from the flowers of Nicotiana tabacum L. Phytochem. Lett. 15, 238-244 (2016).

43. Wang, J. et al. Boscartins L-O: Cembrane-type diterpenoids from the gum resin of Boswellia sacra Flueck. Phytochemistry 163, 126-131 (2019).

44. Zhang, X.-W. et al. Two new eunicellin diterpenoids from the South China Sea gorgonian Muricella sibogae and their bioactivities. Nat. Prod. Res. 29, 2018-2023, https://doi.org/10.1080/14786419.2015.1027893 (2015).

45. Ru, T. et al. Further new eunicellin-based diterpenoids from the Guangxi Weizhou soft coral Cladiella krempfi. Fitoterapia 131, 200-203 (2018).

46. Sawant, S. S. et al. Bioactive rearranged and halogenated semisynthetic derivatives of the marine natural product sarcophine. J. Nat. Prod. 67, 2017-2023 (2004).

47. Atlas, R. M. Handbook of microbiological media. (CRC press, 2010).

48. Weisburg, W. G., Barns, S. M., Pelletier, D. A. \& Lane, D. J. 16 S ribosomal DNA amplification for phylogenetic study. J. Bacteriol. 173, 697-703 (1991).

49. Yoon, S.-H. et al. Introducing EzBioCloud: a taxonomically united database of $16 \mathrm{~S}$ rRNA gene sequences and whole-genome assemblies. Int. J. Syst. Evol. Microbiol. 67, 1613 (2017).

50. Tamura, K. et al. MEGA5: Molecular Evolutionary Genetics Analysis Using Maximum Likelihood, Evolutionary Distance, and Maximum Parsimony Methods. Mol. Biol. Evol. 28, 2731-2739, https://doi.org/10.1093/molbev/msr121 (2011).

51. Saitou, N. \& Nei, M. The neighbor-joining method: a new method for reconstructing phylogenetic trees. Mol. Biol. Evol. 4, 406-425, https://doi.org/10.1093/oxfordjournals.molbev.a040454 (1987).

52. Felsenstein, J. Evolutionary trees from DNA sequences: A maximum likelihood approach. J. Mol. Evol. 17, 368-376, https://doi. org/10.1007/bf01734359 (1981)

53. Fitch, W. M. Toward defining the course of evolution: minimum change for a specific tree topology. Syst. Biol. 20, 406-416 (1971).

54. Pruesse, E., Peplies, J. \& Glöckner, F. O. SINA: Accurate high-throughput multiple sequence alignment of ribosomal RNA genes. Bioinforma. 28, 1823-1829, https://doi.org/10.1093/bioinformatics/bts252 (2012).

55. Ludwig, W. et al. ARB: a software environment for sequence data. Nucleic Acids Res. 32, 1363-1371, https://doi.org/10.1093/nar/ gkh293 (2004).

56. Fu, G. Y. et al. Mesorhizobium oceanicum sp. nov., isolated from deep seawater. Int. J. Syst. Evol. Microbiol. 67, 2739-2745 (2017).

57. Brettin, T. et al. RASTtk: a modular and extensible implementation of the RAST algorithm for building custom annotation pipelines and annotating batches of genomes. Sci. Rep. 5, 8365 (2015).

58. Lee, I., Kim, Y. O., Park, S.-C. \& Chun, J. OrthoANI: an improved algorithm and software for calculating average nucleotide identity. Int. J. Syst. Evol. Microbiol. 66, 1100-1103 (2016).

59. Meier-Kolthoff, J. P., Auch, A. F., Klenk, H.-P. \& Göker, M. Genome sequence-based species delimitation with confidence intervals and improved distance functions. BMC Bioinforma. 14, 60 (2013).

60. Consortium, U. UniProt: a hub for protein information. Nucleic Acids Res. 43, D204-D212 (2014).

61. Kanehisa, M., Sato, Y., Kawashima, M., Furumichi, M. \& Tanabe, M. KEGG as a reference resource for gene and protein annotation. Nucleic Acids Res. 44, D457-D462 (2015).

62. Ashburner, M. et al. Gene ontology: tool for the unification of biology. Nat. Genet. 25, 25 (2000).

63. Galperin, M. Y., Makarova, K. S., Wolf, Y. I. \& Koonin, E. V. Expanded microbial genome coverage and improved protein family annotation in the COG database. Nucleic Acids Res. 43, D261-D269 (2014).

64. Lowe, T. M. \& Eddy, S. R. tRNAscan-SE: a program for improved detection of transfer RNA genes in genomic sequence. Nucleic Acids Res. 25, 955-964 (1997).

65. Lagesen, K. et al. RNAmmer: consistent and rapid annotation of ribosomal RNA genes. Nucleic Acids Res. 35, 3100-3108 (2007). 
66. Grissa, I., Vergnaud, G. \& Pourcel, C. CRISPRFinder: a web tool to identify clustered regularly interspaced short palindromic repeats. Nucleic Acids Res. 35, W52-W57 (2007).

67. Blin, K. et al. antiSMASH 5.0: updates to the secondary metabolite genome mining pipeline. Nucleic Acids Res, https://doi. org/10.1093/nar/gkz310 (2019).

68. Williams, S. et al. Numerical classification of Streptomyces and related genera. Microbiology 129, 1743-1813 (1983).

69. Kelly, K. L. \& Judd, D. B. ISCC-NBS color-name charts illustrated with centroid colors (1965).

70. Sun, C., Pan, J., Zhang, X. Q., Su, Y. \& Wu, M. Pseudoroseovarius zhejiangensis gen. nov., sp. nov., a novel alpha-proteobacterium isolated from the chemical wastewater, and reclassification of Roseovarius crassostreae as Pseudoroseovarius crassostreae comb. nov., Roseovarius sediminilitoris as Pseudoroseovarius sediminilitoris comb. nov. and Roseovarius halocynthiae as Pseudoroseovarius halocynthiae comb. nov. Anton Leeuw 108, 291-299, https://doi.org/10.1007/s10482-015-0480-9 (2015).

71. Chen, C. et al. Streptomyces nigra sp. nov. is a Novel Actinobacterium Isolated from Mangrove Soil and Exerts a Potent Antitumor Activity in vitro. Front Microbiol 9 (2018).

72. Dong, X. \& Cai, M. (Beijing: Scientific Press (English translation) (2001).

73. Lányi, B. In Methods in Microbiology Vol. 19 (eds R. R. Colwell \& R. Grigorova) 1-67 (Academic Press, 1988).

74. Kuykendall, L. D., Roy, M. A., O’Neill, J. J. \& Devine, T. E. Fatty Acids, Antibiotic Resistance, and Deoxyribonucleic Acid Homology Groups of Bradyrhizobium japonicum. Int. J. Syst. Evol. Microbiol. 38, 358-361, https://doi.org/10.1099/00207713-38-4-358 (1988).

75. Komagata, K. \& Suzuki, K. I. In Methods in Microbiology Vol. 19 (eds R. R. Colwell \& R. Grigorova) 161-207 (Academic Press, 1988).

76. Tindall, B. Lipid composition of Halobacterium lacusprofundi. FEMS Microbiol. Lett. 66, 199-202 (1990).

77. Lechevalier, M. E. \& Lechevalier, H. A. The chemotaxonomy of Actinomycetes in Actinomycete Taxonomy. Arlington: Soc. Ind. microbiology 1, 980 (1980).

78. Wang, J. et al. Five new epothilone metabolites from Sorangium cellulosum strain So0157-2. J. Antibiot. 62, 483 (2009).

79. Huang, H. et al. Micromonospora rifamycinica sp. nov., a novel actinomycete from mangrove sediment. Int. J. Syst. Evol. Microbiol. 58, 17-20 (2008).

80. Ren, J. et al. Micromonospora wenchangensis sp. nov., isolated from mangrove soil. Int. J. Syst. Evol. Microbiol. 63, 2389-2395, https://doi.org/10.1099/ijs.0.045476-0 (2013).

\section{Acknowledgements}

We thank Yu Liu (College of Life Sciences, Zhejiang University) for performing NMR spectrometry and Bioultrastructure analysis lab of Analysis Center of Agrobiology and Environmental Sciences (Zhejiang Universty) for conducting the scanning electron micrographs. This work was supported by Si Yuan Foundation (Research on antitumor compounds from marine microorganisms), the National Natural Science Foundation of China (grant no. 31770007) and the Research on Environmental Management Plan and APEI Construction Scheme in Haishan District (DY135-E2-2-05).

\section{Author contributions}

G.F. conducted most of the experiments, analyzed the results and wrote the manuscript under the guidance of M.W. and J.W. R.W. and Q.H. tested the biological activities. J.D., H.Z. and Z.X. performed the spectroscopic data analysis. Z.Z. and C.C. undertook the genome analysis.

\section{Competing interests}

The authors declare no competing interests.

\section{Additional information}

Supplementary information is available for this paper at https://doi.org/10.1038/s41598-020-60677-0.

Correspondence and requests for materials should be addressed to J.W. or M.W.

Reprints and permissions information is available at www.nature.com/reprints.

Publisher's note Springer Nature remains neutral with regard to jurisdictional claims in published maps and institutional affiliations.

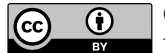

Open Access This article is licensed under a Creative Commons Attribution 4.0 International

License, which permits use, sharing, adaptation, distribution and reproduction in any medium or format, as long as you give appropriate credit to the original author(s) and the source, provide a link to the Creative Commons license, and indicate if changes were made. The images or other third party material in this article are included in the article's Creative Commons license, unless indicated otherwise in a credit line to the material. If material is not included in the article's Creative Commons license and your intended use is not permitted by statutory regulation or exceeds the permitted use, you will need to obtain permission directly from the copyright holder. To view a copy of this license, visit http://creativecommons.org/licenses/by/4.0/.

(c) The Author(s) 2020 